\title{
DAMPAK PROGRAM KAWASAN RUMAH PANGAN LESTARI (KRPL) TERHADAP PENGELUARAN KONSUMSI RUMAH TANGGA (Studi Kasus Di Desa Pucangsari Kecamatan Purwodadi Kabupaten Pasuruan)
}

\author{
Teguh Sarwo Aji, Mu'munatus Sholihah \\ Fakultas Pertanian Universitas Yudharta Pasuruan \\ teguh@yudharta.ac.id
}

\begin{abstract}
ABSTRAK
Penelitian ini bertujuan untuk menganalisis dampak program KRPL terhadap pola konsumsi pangan Rumah Tangga. Variable yang dianalisis yaitu jenis pangan dan asal pangan, kemudian dianalisis dengan menggunakan regresi linier berganda. Jumlah responden yang diambil sebanyak 58 Rumah Tangga, jumlah tersebut adalah total dari semua populasi. Dari hasil analisis pengeluaran bahwasannya rumah tangga sebelum menjadi anggota KRPL mempunyai pengeluaran rata-rata sebesar 650.000-700.000 /bulan/RT, sedangkan RT setelah menjadi anggota KRPL mempunyai pengeluaran rata-rata sebesar 550.000 - 600.000 /bulan/RT. Dari hasil analisis regresi diketahui hasil Uji t pada variabel jenis pangan 3.797> $t_{\text {tabel }}$ 1,676. Sedangkan hasil uji F 17,411 > dari f table 3,18. Artinya program KRPL berdampak pada pengeluaran konsumsi pangan rumah tangga.
\end{abstract}

Kata Kunci: KRPL, pengeluaran, konsumsi pangan

\section{PENDAHULUAN}

Untuk mencapai ketahanan pangan diperlukan ketersediaan pangan dalam jumlah dan kualitas yang cukup, terdistribusi dengan harga terjangkau dan aman dikonsumsi bagi setiap warga untuk menopang aktivitasnya sehari-hari sepanjang waktu. Konsep ketahanan pangan selalu identik dengan ukuran kemandirian pangan, yakni terpenuhinya kebutuhan pangan (nasional/kawasan) secara mandiri dengan memberdayakan modal manusia, sosial dan ekonomi (termasuk lahan pekarangan dan pertanian serta sekitarnya) yang dimiliki, dan berdampak kepada peningkatan kehidupan sosial dan ekonomi masyarakat/petani.

Salah satu daerah Jawa Timur yang ditunjuk sebagai daerah yang akan mengaplikasikan program KRPL adalah Dusun Sudimoro Desa Pucangsari, Kecamatan Purwodadi, Kabupaten Pasuruan. Seperti tujuan KRPL pada awalnya yakni untuk pemenuhan kebutuhan pangan dan gizi keluarga, mengurangi biaya pengeluaran rumah tangga, penambahan pendapatan keluarga, dan meningkatkan kesejahteraan.

Program ini kurang lebih sudah berjalan selama satu tahun, dan tentunya sedikit banyak telah memberikan dampak terhadap anggota rumah tangga yang telah menjadi anggota KRPL, oleh karena itu apakah program KRPL ini memang benar benar memberikan dampak yang positif terhadap anggota atau tidak, kami ingin mengetahui dan meneliti lebih detail salah satu poin dari tujuan tersebut yaitu 
mengurangi biaya pengeluaran rumah tangga khususnya pengeluaran pangan, untuk melihat apakah ada perbedaan yang signifikan antara anggota rumah tangga sebelum menjadi anggota KRPL dan setelah menjadi anggota KRPL

\section{METODE PENELITIAN}

\section{Variabel Penelitian}

a. Variabel bebas (independent variabel)

Variabel bebas dalam penelitian ini adalah:
- Faktor jenis pangan (X1)
- Faktor asal pangan (X2)

b. Variabel terikat (dependent variabel)

Yang dijadikan sebagai variabel terikat (Y) dalam penelitian ini adalah pengeluaran konsumsi pangan.

\section{Teknik Analisis Data}

\section{Analisis Regresi Linier Berganda}

Analisis ini digunakan untuk menentukan ketepatan prediksi apakah ada hubungan (pengaruh) yang kuat antara variabel terikat $(\mathrm{Y})$ pengeluaran konsumsi pangan dengan variabel bebas (X) faktor pangan, adapun rumus regresinya sebagai berikut:

$$
\mathrm{Y}=\alpha+\beta 1 \mathrm{X} 1+\beta 2 \mathrm{X} 2+\beta 3 \mathrm{X} 3+\varepsilon
$$

Keterangan:

$\mathrm{Y}=$ pengeluaran konsumsi pangan

A $=$ Konstanta

$\mathrm{X} 1=$ Faktor jenis pangan

$\mathrm{X} 2=$ Faktor asal pangan

X3 = Faktor tingkat konsumsi pangan $\beta 1-\beta 3=$ Besaran koefisien dari masingmasing variabel

$\varepsilon \quad=$ Error

\section{Pengujian Hipotesis}

\section{a) Uji F (Uji Simultan)}

Uji F merupakan alat uji statistik secara simultan untuk mengetahui pengaruh variabel bebas terhadap variabel terikat secara bersama-sama.

Hipotesis penelitian sebagai berikut:

Ho:b1=0;b2 $=0$ Artinya secara simultan tidak ada pengaruh yang signifikan variabel pengeluaran konsumsi pangan di daerah wilayah KRPL terhadap faktor pangan (koefisien regresi non signifikan).

Ha:b1 $\neq 0 ; b 2=$ Artinya secara simultan ada pengaruh yang signifikan variabel pengeluaran konsumsi pangan di daerah wilayah KRPL terhadap faktor pangan (koefisien regresi non signifikan).

Kriteria pngujian adalah sebagai berikut:

Ho diterima dan Ha ditolak jika : f hitung < $\mathrm{f}$ tabel atau nilai probabilitas $>5 \%$

Ho ditolak dan Ha diterima jika : $\mathrm{f}$ hitung $>\mathrm{f}$ tabel atau nilai probabilitas $<5 \%$

\section{b) Uji t (Uji Parsial)}

Uji t merupakan alat uji statistik secara individu untuk mengetahui pengaruh masingmasing variabel bebas terhadap variabel terikat yaitu variabel faktor pangan terhadap pengeluaran konsumsi pangan.

Hipotesis penelitian sebagai berikut: 
Ho:b1=0 Artinya pengaruh parsial tidak signifikan

Ha:b1 $\neq 0$ Artinya pengaruh parsial terbukti signifikan

Kriteria pengujiannya sebagai

berikut:

\section{HASIL DAN PEMBAHASAN}

\section{Analisis Regresi Linier Berganda}

Regresi linear berganda dilakukan untuk menganalisis dampak program KRPL terhadap pengeluaran rumah tangga. Model analisis ini digunakan untuk mengetahui
Ho diterima dan Ha ditolak jika : $\mathrm{t}$ hitung $<\mathrm{t}$ tabel atau nilai probabilitas $>5 \%$

Ho ditolak dan Ha diterima jika : $\mathrm{t}$ hitung $>\mathrm{t}$ tabel atau nilai probabilitas $<5 \%$

Tabel 1. Anova Regresi Linier Berganda

Coefficients $^{\mathbf{a}}$

\begin{tabular}{|c|c|c|c|c|c|c|c|}
\hline \multirow[b]{2}{*}{ odel } & \multicolumn{2}{|c|}{ Unstandardized Coefficients } & \multicolumn{2}{|l|}{$\begin{array}{l}\text { Standardized } \\
\text { Coefficients }\end{array}$} & \multirow[b]{2}{*}{ Sig. } & \multicolumn{2}{|c|}{ Collinearity Statistic } \\
\hline & B & Std. Error & Beta & $\mathrm{t}$ & & Tolerance & VIF \\
\hline (Constant) & .776 & 1.124 & & .690 & .493 & & \\
\hline $\begin{array}{l}\text { X1 } \\
\text { (jenis pangan) }\end{array}$ & .322 & .085 & .430 & 3.797 & .000 & .868 & 1.1 \\
\hline $\begin{array}{l}\mathrm{X} 2 \\
\text { (asal pangan) }\end{array}$ & .216 & .076 & .320 & 2.828 & .007 & .868 & 1.1 \\
\hline Dependent Varia & ngeluaran konsı & msi pangan & & & & & \\
\hline
\end{tabular}

Dari tabel di atas dapat dituliskan bahwa persamaan regresi linier berganda:

$$
Y=0.776+0.322 X_{1}+0.076 X_{2}
$$

Persamaan di atas mengandung arti sebagai berikut:

$\mathrm{a}=0.776$ artinya apabila tidak ada perubahan pada variabel jenis pangan $\left(\mathrm{X}_{1}\right)$, asal pangan $\left(\mathrm{X}_{2}\right)$, maka dampak program KRPL terhadap pengeluaran rumah tangga sebesar 0.776

$b_{1}=0.322$ artinya setiap peningkatan variabel jenis pangan $\left(\mathrm{X}_{1}\right)$ akan berpengaruh besarnya pengaruh variabel bebas terhadap variabel terikat. Hasil dari analisis regresi linear berganda dapat dilihat pada tabel dibawah ini : terhadap pengeluaran sebesar 0.776 . artinya apabila jenis pangan meningkat, maka pengeluaran rumah tangga juga akan semakin meningkat sebesar 0.776 .

$\mathrm{b}_{2}=0.076$ artinya setiap peningkatan variabel asal pangan $\left(\mathrm{X}_{2}\right)$ akan berpengaruh terhadap pengeluaran konsumsi rumah tangga sebesar 0.076. artinya apabila asal pangan meningkat, maka pengeluaran konsumsi rumah 
tangga juga akan akan mengalami peningkatan sebesar 0.076 .

\section{Pengujian Hipotesis}

Uji t

Dari tabel dibawah ini (tabel 2) dapat dilihat bahwa variabel jenis pangan $\left(\mathrm{X}_{1}\right)$ mempunyai nilai $t$ hitung sebesar 3.797> dari $\mathrm{t}_{\text {tabel }}$ sebesar 1,676, variabel asal pangan $\left(\mathrm{X}_{2}\right)$ mempunyai $t_{\text {hitung }}$ sebesar $2.828>t_{\text {tabel }}$ sebesar 1,676 , artinya secara parsial variabel bebas jenis pangan $\left(\mathrm{X}_{1}\right)$, asal pangan $\left(\mathrm{X}_{2}\right)$, berpengaruh positive dan signifikan terhadap pengeluaran konsumsi pangan rumah tangga (Y), pada signifikansi 0,05 atau $5 \%$. Sehingga dapat disimpulkan bahwa variabel.

Tabel 2. Hasil Analisis Uji t

Coefficients $^{\mathrm{a}}$

\begin{tabular}{|c|c|c|c|c|c|c|c|c|}
\hline \multirow{2}{*}{\multicolumn{2}{|c|}{ Model }} & \multicolumn{2}{|c|}{$\begin{array}{l}\text { Unstandardized } \\
\text { Coefficients }\end{array}$} & \multirow{2}{*}{$\begin{array}{c}\text { Standardized } \\
\text { Coefficients }\end{array}$} & \multirow[b]{2}{*}{$\mathrm{t}$} & \multirow[b]{2}{*}{ Sig. } & \multicolumn{2}{|c|}{ Collinearity Statistics } \\
\hline & & B & Std. Error & & & & Tolerance & VIF \\
\hline 1 & (Constant) & .776 & 1.124 & & .690 & .493 & & \\
\hline & $\mathrm{X} 1$ (jenis pangan) & .322 & .085 & 430 & 3.797 & .000 & .868 & 1.152 \\
\hline & X2(asal pangan) & .216 & .076 & .320 & 2.828 & .007 & .868 & 1.152 \\
\hline
\end{tabular}

a. Dependent Variable: pengeluaran konsumsi pangan rumah tangga

Sumber : Data Primer diolah (2013)

Untuk mengetahui apakah variabel $\mathrm{Y}$ (pengeluaran) dipengaruhi oleh $\mathrm{X}_{1}$ (jenis pangan), $X_{2}$ (asal pangan) ataukah tidak, bisa dilihat dari perbandingan nilai $\mathrm{F}_{\text {hitung }}$ dengan $F_{\text {tabel }}$ nya. Bila $F_{\text {hitung }}$ lebih besar dari $F_{\text {tabel }}$, maka $\mathrm{Y}$ (pengeluaran) dipengaruhi oleh $\mathrm{X}_{1}$ (jenis pangan), $\mathrm{X}_{2}$ (asal pangan). Namun bila
$F_{\text {hitung }}$ lebih kecil dari $F_{\text {tabel, }}$ maka $\mathrm{Y}$ (pengeluaran) tidak dipengaruhi oleh $X_{1}$ (jenis pangan), $X_{2}$ (asal pangan). Hal ini juga dapat dilakukan dengan membandingkan nilai signifikansi dengan $\alpha(0,05)$. Bila nilai sig $<0.05$ signifikan, bila nilai sig $>0.05$ tidak signifikan.

Tabel 3. Hasil Analisis Uji F

ANOVA $^{\text {b }}$

\begin{tabular}{lrrrrrr}
\hline & & & & & F \\
Iodel & Sum of Squares & df & Mean Square & F & tabel & Sig. \\
\hline Regression & 32.217 & 2 & 16.109 & $17.4113,18$ & .000 \\
Residual & 50.886 & 55 & .925 & & \\
Total & 83.103 & 57 & & & \\
\hline
\end{tabular}

a. Predictors: (Constant), X2, X1

b. Dependent Variable: Y

Sumber : Data Primer Diolah (2013) 
Dari hasil perhitungan pada tabel diatas dapat dilihat bahwa $f$ hitung menunjukkan nilai sebesar 17,411 dan signifikansi $\mathrm{f}=0,000^{\mathrm{a}}$. Dimana $\mathrm{f}$ hitung $>\mathrm{f}$ tabel $(17,411 \quad>3,18)$ dan $\quad$ sig $\quad F<5 \%$ $(0,000<0,05)$, artinya bahwa secara simultan variabel faktor jenis pangan (X1) dan faktor

\section{KESIMPULAN}

Berdasarkan hasil analisis diatas dapat disimpulkan bahwa program KRPL di desa pucangsari memang memberikan dampak yang signifikan pada pengeluaran konsumsi rumah tangga, hal ini dapat dilihat pada hasil analisis tadi dari faktor jenis pangan dan asal pangan. factor asal pangan contohnya, yang sebelumnya warga harus memenuhi kebutuhan makanan berjenis sayur-sayuran

\section{DAFTAR PUSTAKA}

Anonimus. 2012. Pengertian Pola Pangan Harapan(http://semutuyet.blogspot.co $\underline{m / 2012 / 05 /}$

Pengertian-pola panganharapan.html) Diakses pada : 10 Juli 2013

Anonimus. 2013. Pengeluaran Konsumsi

$\begin{array}{lr}\text { Rumah } & \text { tangga. } \\ \text { (http://sirusa.bps.go.id). } & \text { Diakses } \\ \text { pada : 10 Juli 2013 } & \end{array}$

asal pangan (X2) berpengaruh signifikan terhadap pengeluaran $(\mathrm{Y})$.

Dengan demikian hipotesis yang menduga bahwa secara simultan variabel faktor jenis pangan (X1) dan faktor assal pangan (X2) berpengaruh signifikan terhadap pengeluaran $(\mathrm{Y})$ "diterima".

dan lauk pauk dengan cara membeli, akan tetapi setelah mereka menjadi anggota KRPL kebutuhan tersebut dapat dipenuhi dari pekarangan warga sendiri. Jadi KRPL sedikit banyak telah memberikan dampak yang signifikan terhadap pengeluaran konsumsi pangan rumah tangga, sesuai dengan tujuan peneliti yaitu untuk mengetahui dampak program KRPL terhadap pengeluaran konsumsi rumah tangga.

Anonimus. 2012. Kawasan Rumah Pangan Lestari-KRPL. (hhp://www.litbang.deptan.go.id/krpl ) Diakses pada : 10 Juli 2013

Anonimus. 2012. Pengertian Konsumsi. (http://ilmugreen.blogspot.com)

Diakses pada : 10 Juli 2013

Badan Litbang Pertanian. 2012. Pengembangan Kawasan Rumah Pangan Lestari (KRPL). Badan Penelitian dan Pengembangan Pertanian. Jakarta. 